\title{
Mechanical performance of strain-hardening cementitious composites (SHCC) with bacterial addition
}

Zhigang Zhang ${ }^{1,2}$, Dawei Liu' ${ }^{1}$ Yuanzhao Ding ${ }^{2}$ and Shuping Wang ${ }^{3^{*}}$

\begin{abstract}
Incorporation of bacteria can realize self-healing and enhance strength of concrete, which has been drawn extensive attention in past decades. The studies focused on the properties of fiber reinforced concrete with bacterial addition are still very limited. In this paper, mechanical performance of strain hardening cementitious composites (SHCC) with directly adding vegetative bacterial cells was investigated. The experimental results revealed that the compressive, first cracking, and tensile strength of SHCCs was increased due to the addition of bacteria, while the tensile strain capacity tended to decline. At micro-scale level, the matrix containing bacteria has relative higher fracture toughness to that of reference mix. Interestingly, the bacteria notably lowered chemical bond between PVA fiber and its surrounding hydrates; on the other hand, the frictional bond was enhanced. The findings in this study can provide a reference for modifying the surface of hydrophilic fibers.
\end{abstract}

Keywords: SHCC, Mechanical performance, Bacteria; micro-scale

\section{Introduction}

Concrete is the second most consumed substance in the world only after water, duo to its high strength, low cost, and easy availability worldwide et al. It contributes greatly to the infrastructures, and is the foundation of modern development, providing a solid and safe structure for the daily life of people. However, with the development of modern society, the requirements to concrete are always raising in different aspects. In the past decades, researchers have been devoting to improve the performance of concrete, such as high strength, ductility, flowability, durability, and some specific functionality et al.

To improve the fracture toughness, adding fibers into concrete can increase its value by an order of magnitude, meanwhile, it can also effectively mitigate the early cracking phenomenon upon shrinkage. On the other hand, the

\footnotetext{
*Correspondence: shuping@cqu.edu.cn

${ }^{3}$ College of Materials Science and Engineering, Chongqing University,

Chongqing 400045, China

Full list of author information is available at the end of the article
}

tensile ductility of concrete still remain little altered, to convert the quasibrittle feature of concrete, strain hardening cementitious composites (SHCC) or engineered cementitious composites (ECC) was developed by $\mathrm{Li}$ and his coworkers in the 1990s. The SHCC exhibits high tensile strain capacity of $3 \sim 10 \%$ at moderate fiber volume [1-4], which transform the brittle failure of concrete into ductile damage mode. Under tension, it develops multiple micro-cracks on SHCC specimens instead of one single localized fracture crack that in conventional concrete $[5,6]$. Typically, the crack width of SHCC can be controlled below $100 \mu \mathrm{m}$ [1], interestingly; this kind of tight cracks on SHCC can heal itself autogenously as the continue reaction of binder materials under moisture circumstance $[7,8]$. However, only very tight cracks that below $50 \mu \mathrm{m}$ can be filled by healing products fully upon the autogenously self-healing, while the complete selfhealing in SHCC was rarely observed when crack width exceeds $100 \mu \mathrm{m}$ [9].

In addition, bacteria technique is also one of the strategies to improve concrete properties. Normally, 
incorporating bacteria into concrete can realize selfhealing by virtue of microbiologically induced calcite precipitation (MICP). It has been widely reported that the millimeter-sized cracks in concrete can be healed by adding bacteria. To ensure the viability of bacteria in the high alkaline environment, a protective carrier is applausive to immobilize or encapsulate bacterial cells. Khaliq et al. immobilized bacterial in light weight aggregate, and found the crack with $0.61 \mathrm{~mm}$ wide can be healed [10]. Moreover, the diatomaceous earth, zeolite, ant expanded perlite can also be a good carrier to ensure the occurrence of efficient self-healing in concrete [11-13]. Wang et al. synthesized microcapsules based on hydrogel and poly-condensation reaction as the carrier, and found that the maximally healable crack can reach $0.97 \mathrm{~mm}$ in width [14].

Compared with the advantage of self-healing, the incorporation of carriers is likely to reduce the strength performance of concrete. Some researchers added the bacterial cells directly into concrete during mixing. It was found that the crack with $0.3 \mathrm{~mm}$ in width can still be healed by the adding bacteria directly, although the maximum healable crack width was reduced [15], on the other hand, the calcium carbonate content in concrete had an evident increase, as a result, the compressive strength of concrete was enhanced [16]. Furthermore, Ghosh et al. [17] incorporated the nutrition culture with inclusion of bacterial cells into concrete or mortar by replacing mixing water, and found that the compressive strength raised in comparison with concrete mixed with water.

In previous studies, some research outcomes related to the fiber reinforced concrete (FRC) with addition of bacteria were gained as well. In those investigations, the original intention of adding fibers into bacterial concrete is for a better self-healing due to the restraint of crack width $[18,19]$. The results showed that the addition of bacteria could reduce the concrete penetrability because of the calcite sediments [20], moreover, the interfacial bond between fiber and cement matrix can be enhanced [21], and subsequently improved the flexural and split tensile strength of FRC $[19,22]$. However, the findings about effect of bacterial adding on the deformation capacity of FRC are still very limited, especially for the SHCC. The authors found that the bacterial incorporation promoted the multiple cracking phenomena in SHCC with high-volume fly ash, and showed a comparable strain capacity to that of control SHCC mixture [23]. Nevertheless, it is well known that the fly ash content can significantly affect the balance among the fiber, matrix, and fiber/matrix interfacial properties; therefore the mechanical performance of SHCC with different fly ash contents may vary a lot $[24,25]$. It is desirable to further explore the influence of bacterial addition on the performance of SHCC with moderate fly ash content.

In this study, incorporating bacterial technique into SHCC is a promising approach to enhance its self-healing capacity, especially for the wide crack that exceeds $100 \mu \mathrm{m}$. To avoid the negative impact on strength, the bacterial culture was adopted to substitute water during mix process of SHCC. The direct incorporation of bacteria may also cause the changes in aspects of matrix and matrix/fiber interfacial properties at micro-scale, which in turn to affect mechanical performance of SHCC. This paper emphasized on investigating the effect of bacterial addition on mechanical performance of SHCC at multiple-scales. In the following sections, the compressive strength and tensile properties of SHCCs will be investigated. In the final, the variations of bacteria on fracture toughness of matrix and fiber/matrix interface was discussed at micro-scale level.

\section{Experimental programs} Materials and mix proportions

In this paper, the ingredients in preparation of SHCC include Portland cement with strength grade of CEM42.5 , fly ash, fly ash cenosphere (FAC), water or bacterial cultures, superplasticizer (SP), and PVA fibers. Table 1 lists the mix proportion of the three SHCC mixtures. The FAC was adopted to substitute the silica sand which was the classic ingredient in preparation of SHCC by equal volume. The FAC has a hollow spherical microstructure which is expected to act as small flaws in SHCC that has been approved to facilitate the initiation of cracks, and thus ductility $[24,26]$. The FAC has a bulk density

Table 1 Mix proportion of SHCC mixtures (g/L)

\begin{tabular}{lllllll}
\hline Mixtures & Cement & Fly ash & FAC & Mixing Liquid & SP & PVA fiber \\
\hline Ref.-SHCC & 388 & 854 & 130 & $\begin{array}{l}318 \\
\text { (Water) }\end{array}$ & 26 \\
W-SHCC & 388 & 854 & 130 & $\begin{array}{l}327 \\
\text { (Wild bacterial culture) }\end{array}$ & 4 \\
M-SHCC & 388 & 854 & 130 & $\begin{array}{l}327 \\
\text { (Mutant bacterial culture) }\end{array}$ & 4 \\
\hline
\end{tabular}


of $800 \mathrm{~kg} / \mathrm{m}^{3}$ and all the particles can pass through $\# 80$ sieves. The three SHCC mixtures that used in this study have the same mix a proportion, the only difference is that the mixing liquids. The water was used in the Ref.SHCC, while the bacterial culture that contains nutrition substances was mixed into W-SHCC and M-SHCC. The weight of liquid in W-SHCC and M-SHCC is relative higher to that of Ref.-SHCC to remain constant water content in liquids.

In this study, there are two kind of bacterial strains, which are Bacillus halodurans DSM 497 (wild type from DSMZ, Germany) and the mutant one from wild type strain based on transposon mutagenesis method as clarified in reference $[27,28]$. As expected, the mutant one has a higher bacterial activity than that of wild type strain, which is likely produce more metabolite [28]. The estimated concentration of vegetative cells of wild type and mutant one is $3 \times 10^{8} / \mathrm{ml}$ and $12 \times 10^{8} / \mathrm{ml}$, respectively. The cell concentration was determined by optical density at $600 \mathrm{~nm}$ (OD600) which normally has a positive relationship to the cell concentration [28]. [Notes: $\mathrm{OD} 600=1.0$ means $10^{\wedge} 8 \mathrm{cells} / \mathrm{ml}$ of cell concentration.]

During mixing process, all the solid materials were pre-mixed for 1 min using a shear-type Hobart mixer with capacity of $20 \mathrm{~L}$. The liquid with superplasticizer together was added into the dry mixtures afterwards and mixed for $3 \mathrm{~min}$ to reach a homogeneous status. In the above procedures, the mixing speed is around $60 \mathrm{r} / \mathrm{min}$. Finally, the PVA fibers were added into the paste slowly and mixed of another $3 \mathrm{~min}$ at $198 \mathrm{r} / \mathrm{min}$. After mixing, the SHCC paste was cast into the molds and covered by plastic sheets before demolding. Then all the specimens were cured in air until 28 days.

\section{Experimental procedures}

Compressive test was performed on the cubic samples complying with ASTM C109 to measure the compressive strength of SHCCs [29]. The cubic samples have a dimension of $50.8 \mathrm{~mm} \times 50.8 \mathrm{~mm} \times 50.8 \mathrm{~mm}$. The compressive strength of SHCC was obtained by averaging three samples for each mixture.

Uniaxial tensile test was employed to characterize the tensile performance of SHCCs. Figure 1 shows the tensile test set-up. The dogbone shaped specimen was adopted for the tensile test. The dimension of the section within gauge length is $80 \mathrm{~mm} \times 30 \mathrm{~mm} \times 15 \mathrm{~mm}$. The relative smaller cross-section is likely to lure the occurrence of cracking within gauge length. To gain the accurate deformation for strain calculation, two external LVDTs were attached to tested specimens. The loading rate is $0.5 \mathrm{~mm} /$ $\min$.

Three-point bending test was conducted to measure the fracture toughness of SHCC matrix (without fibers)

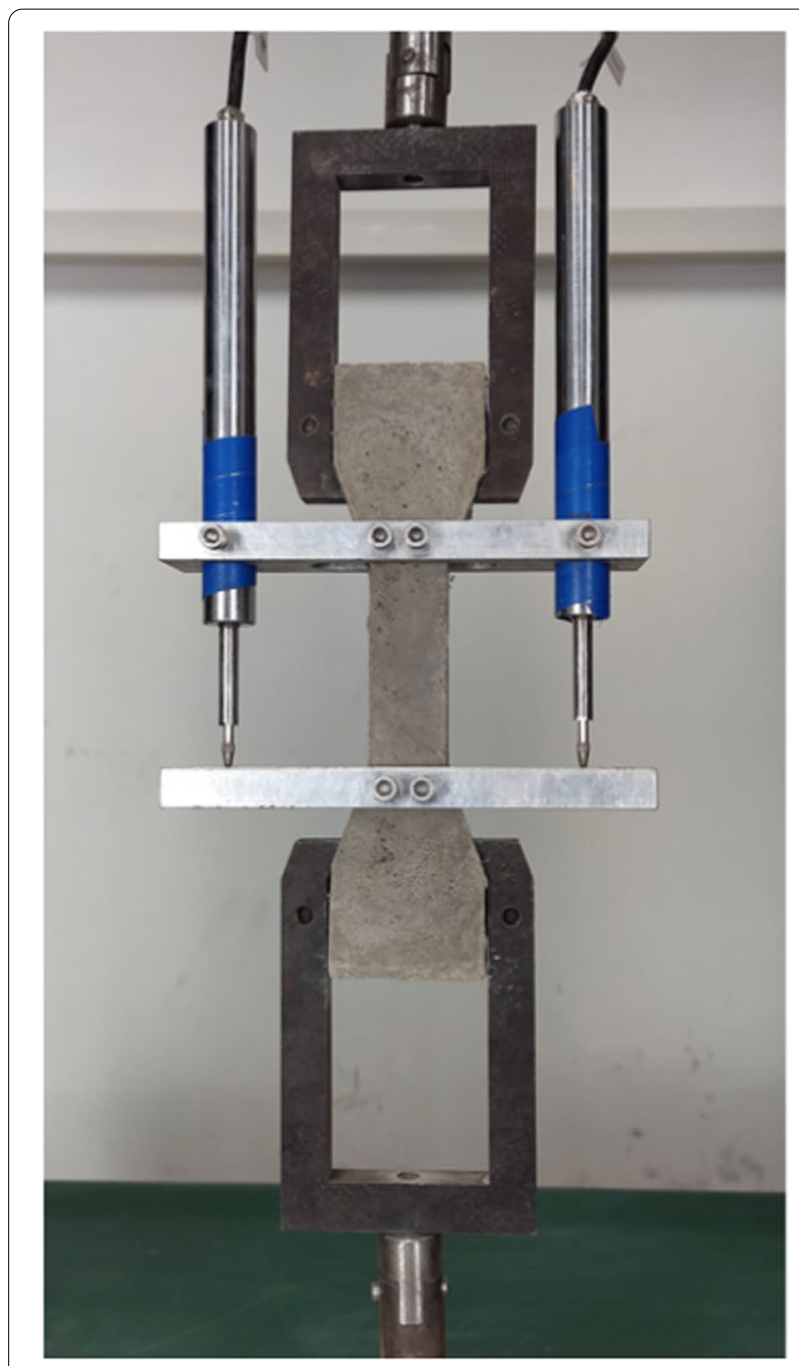

Fig. 1 Tensile test set-up

in accordance with ASTM E399 [30]. The dimension of prism specimen is $305 \mathrm{~mm}$ (length) $\times 38 \mathrm{~mm}$ (width) $\times 76 \mathrm{~mm}$ (height). The test set-up can be found in reference [31]. Prior to test, the notch with depth to beam height of 0.4 was produced using saw. During test, the full span length is $254 \mathrm{~mm}$, and the loading point is located above the notch.

Single fiber pull-out test was conducted to gain the matrix/fiber interfacial properties. From this test, the parameters including chemical bond $\left(G_{d}\right)$, frictional force $\left(\tau_{0}\right)$, and slip-hardening coefficient $(\beta)$ between matrix and PVA fiber can be obtained. During preparation of samples, long fibers were embedded in SHCC matrix, and then the samples were cut into slices with thickness around $1 \mathrm{~mm}$ by using a precision saw before test at 28 days. For each mixture, at least 8 slice samples 


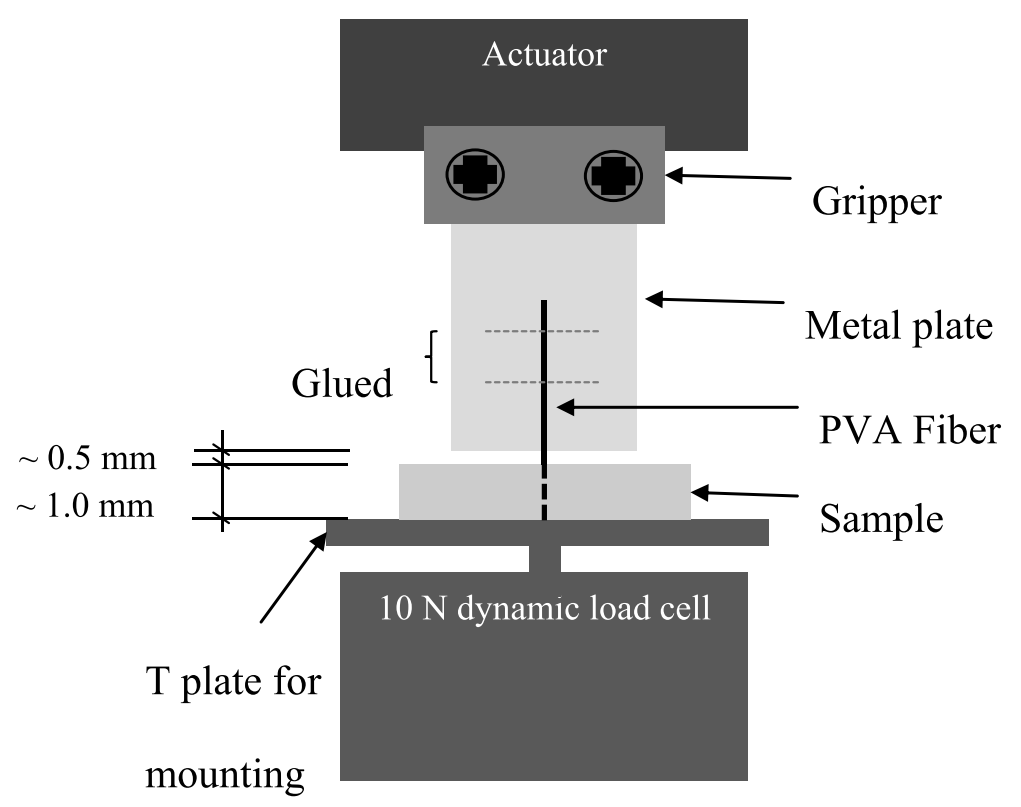

Fig. 2 Illustration of the test set-up

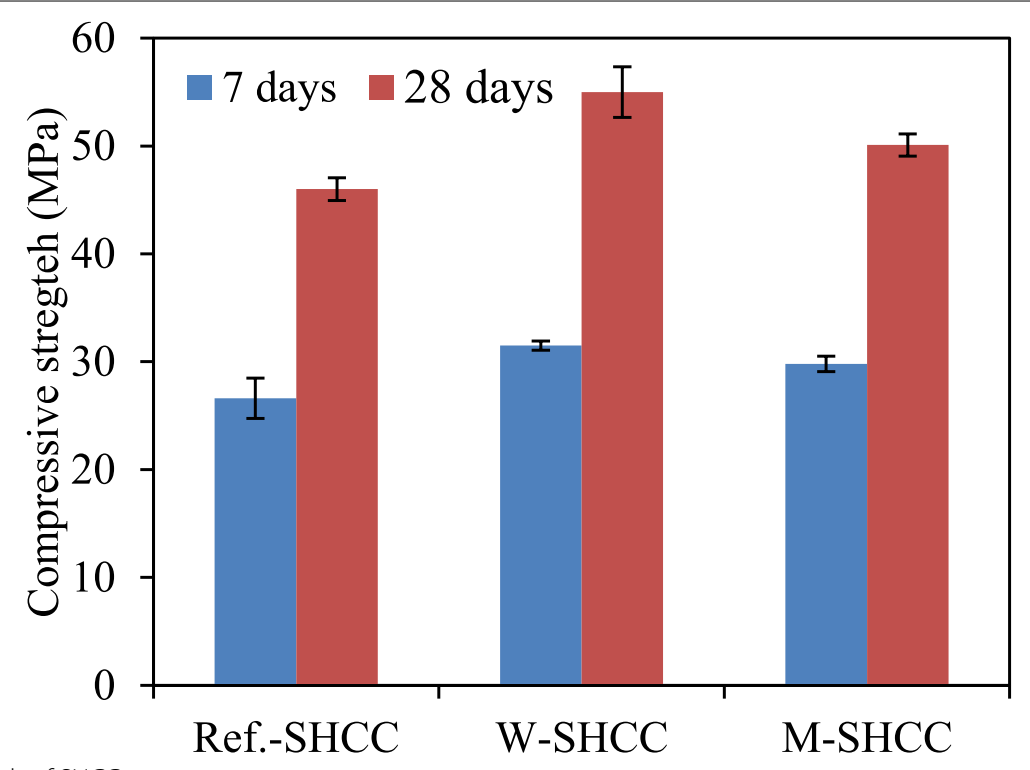

Fig. 3 Compressive strength of SHCCS

were prepared for subsequent calculation of mean value of interfacial parameters. The illustration of this test set-up is displayed in Fig. 2.

\section{Results and discussions}

\section{Compressive strength of SHCCs}

Figure 3 shows the compressive strength of SHCC mixtures at 7 and 28 curing days. It can be found that the addition of bacteria resulted in the increment of compressive strength of SHCCs at both 7 and 28 curing days, among which the SHCC with addition of wild type bacteria strain exhibited highest. It is noted that the harden time of W-SHCC and M-SHCC was delayed significantly due to the nutrient substances in bacterial culture, which was reflected that the specimens of W-SHCC and M-SHCC can't be demolded 
until 3 curing days while that of Ref.-SHCC was demolded at 1 curing day. However, at 7 days, the compressive strength of SHCCs with bacterial addition is higher than that of Ref.-SHCC, which implies that the microbiological motility facilitate the development of strength between 3 to 7 days. At 28 days, the compressive strength of Ref.-SHCC, W-SHCC, and M-SHCC is $46.08 \mathrm{MPa}$, $54.97 \mathrm{MPa}$, and $50.13 \mathrm{MPa}$, respectively, of which the bacterial addition caused $19.29 \%$ and $8.79 \%$ increase, respectively. The relative reduction in compressive strength of M-SHCC as compared to that of W-SHCC may attribute to the varied composition of cultures since the mutant bacteria has more cells and higher activity that consume more nutrition and produce more metabolite [28].

Figure 4 (a) presents the microstructural image on the fractured cross-section of W-SHCC specimen after underwent tensile test. It can be observed that there are extensive calcite-like pieces which are likely the products of biochemical reaction as the $\mathrm{Ca}^{2+}$ can be drawn by the negative charged bacterial cell wall, and thus resulted in the calcite precipitation. Figure 4 (b) illustrated the elemental mapping, which demonstrated the abundant presence of $\mathrm{C}, \mathrm{O}$, and $\mathrm{Ca}$. Based on the element analysis to the products that listed in Table 2, it can be concluded that the small pieces in Fig. 4 (a) is largely calcite. In previous studies, it has been proved that formation of $\mathrm{CaCO}_{3}$ is beneficial to the compressive strength of concrete [32], moreover, the calcite may act filler to refine microstructures of SHCCs [16], which elucidate the enhancement of compressive strength of SHCCs with bacterial addition.

\section{Tensile performance of SHCCs}

Figure 5 displays the relationship between tensile stress and strain of SHCCs. The tensile properties of SHCC include first cracking strength, tensile strength, and strain capacity can be derived from the curves, which are defined as the maximum tensile stress at the initial linear stage, the ultimate stress and its corresponded strain, respectively. The above properties are illustrated in Fig. 6.

From the curves in Fig. 5, it can be seen that all three SHCC mixtures exhibit the strain-hardening phenomenon under tension which is the unique feature of SHCC materials. The strain capacity of the three SHCC mixtures varies from $0.83 \%$ to $1.40 \%$, among which the Ref.-SHCC shows the highest value while the W-SHCC exhibits the lowest. That is, as compared with $1.40 \%$ of Ref.-SHCC, the addition of wild type bacterial culture leads to the $40 \%$ reduction of strain capacity of SHCC to $0.83 \%$, likewise, the strain capacity of M-SHCC is $1.16 \%$ which is decreased by $17 \%$, but is $40 \%$ higher than that of W-SHCC.

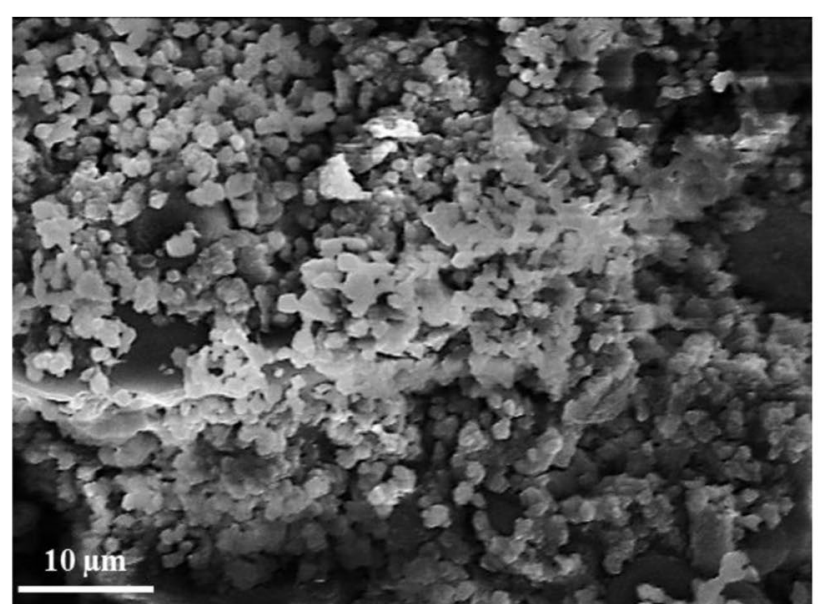

(a)
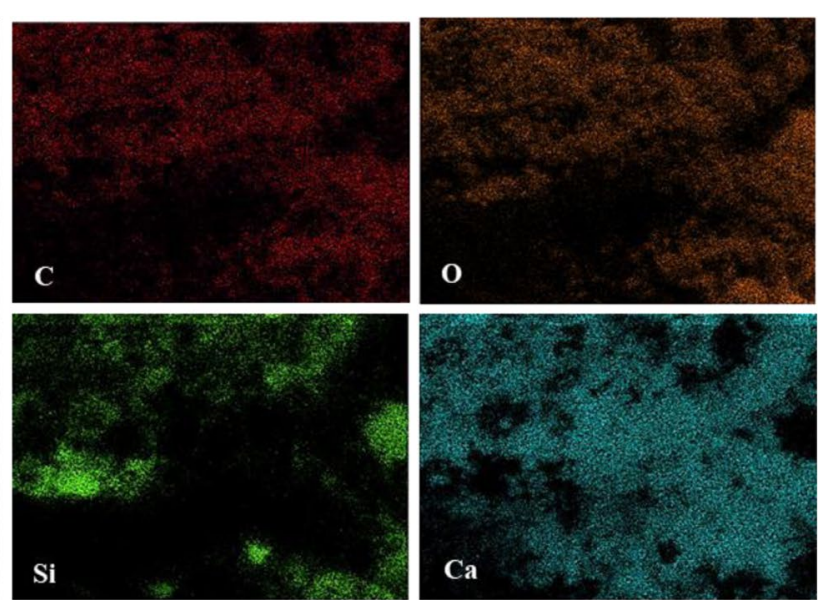

(b)

Fig. 4 a Microstructural image on fractured cross-section of W-SHCC; b Elemental mapping of the products in W-SHCC

Table 2 EDS element analysis of products in Fig. 4

\begin{tabular}{lllllll}
\hline Element & $\mathbf{C}$ & $\mathbf{0}$ & Na & Al & Si & Ca \\
\hline At $\%$ & 22.51 & 60.04 & 1.05 & 2.10 & 4.60 & 9.17 \\
\hline
\end{tabular}




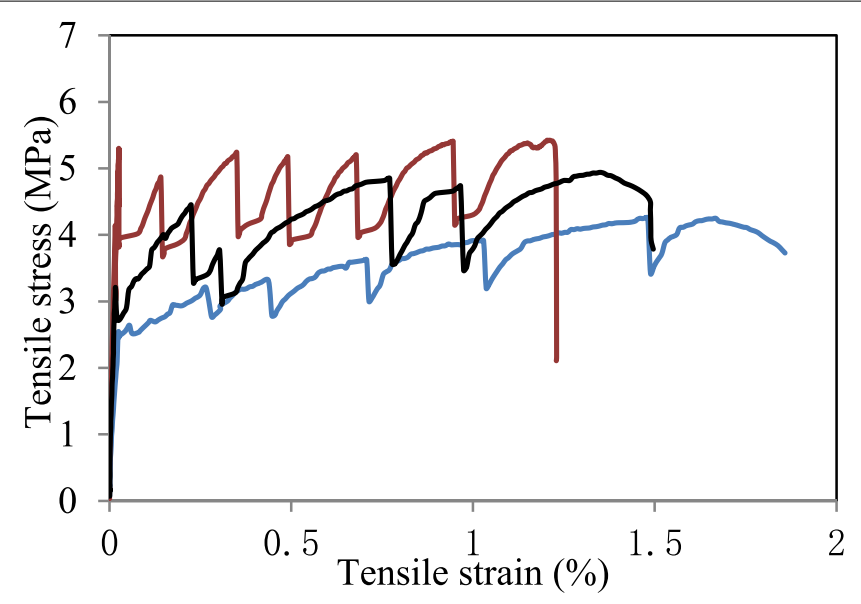

(a)

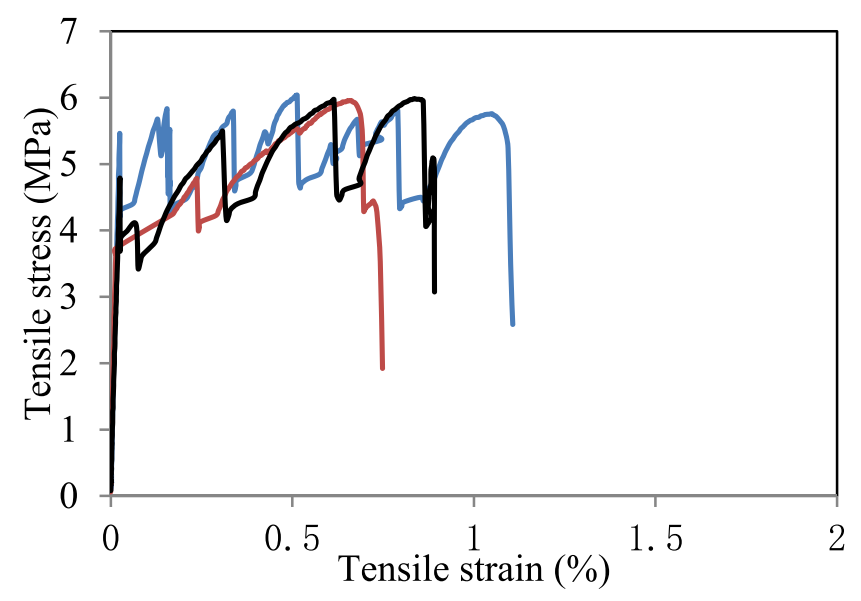

(b)

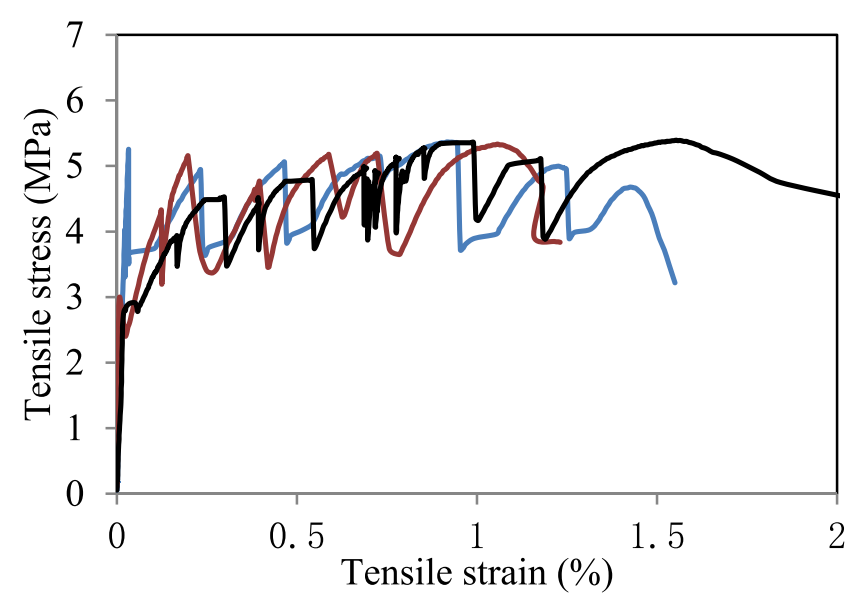

(c)

Fig. 5 Tensile stress-strain relationship of SHCCs: a Ref.-SHCC; $\mathbf{b}$ W-SHCC; c M-SHCC 


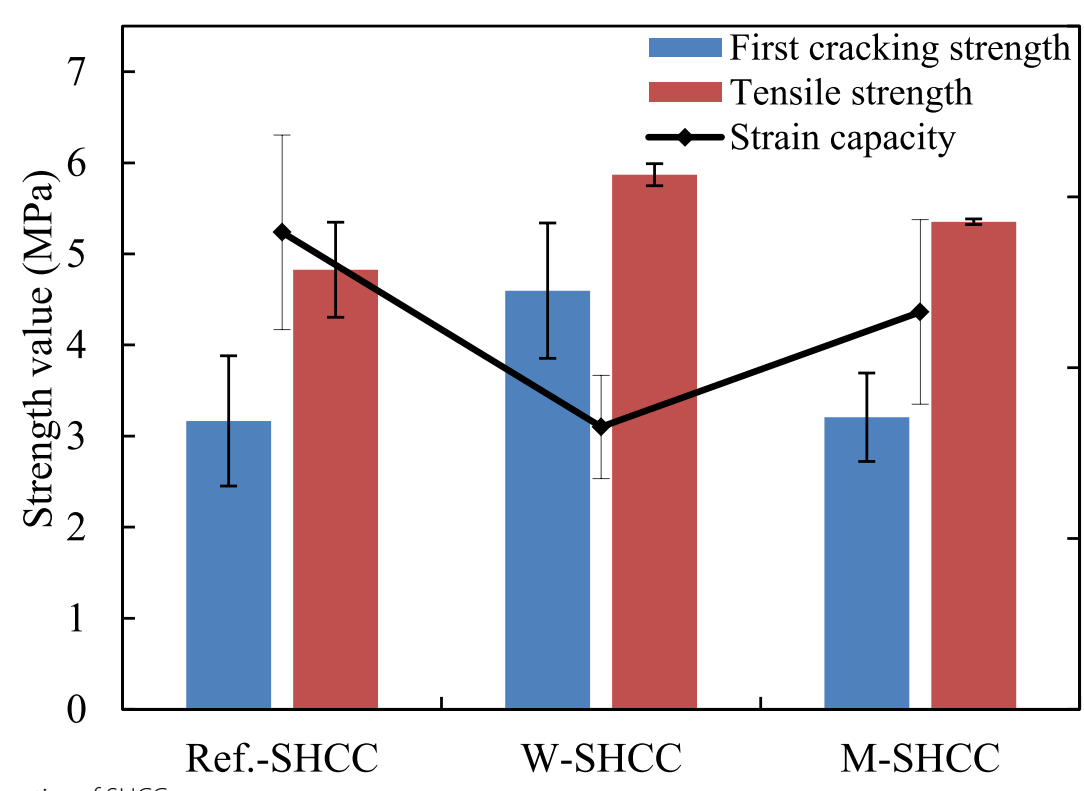

Fig. 6 Tensile properties of SHCCs

As illustrated in Fig. 6, due to the incorporation of bacterial culture, the first cracking and tensile strength of SHCCs shows the similar tendency to that of compressive strength: using bacterial culture to replace water increases strength value of SHCCs, whereas the M-SHCC presents relative lower value to that of W-SHCC. This is because that the compressive and first cracking strength of SHCC is closely associated to matrix performance, and normally, the stress value that can trigger cracks on concrete is proportional relation to compressive strength. In term of tensile strength, it is dominated by the fiber bridging capacity across one crack which is a result of synergistic actions of plentiful single fiber against surrounding hydrates during pull-out process. The alteration in tensile strength implies that the bacterial addition changes the matrix/fiber interfacial properties, which will be discussed in the following section.

\section{Discussions at micro-scale level}

Based on SHCC design theory, to attain high ductility of SHCC, two ways was normally adopted, which are

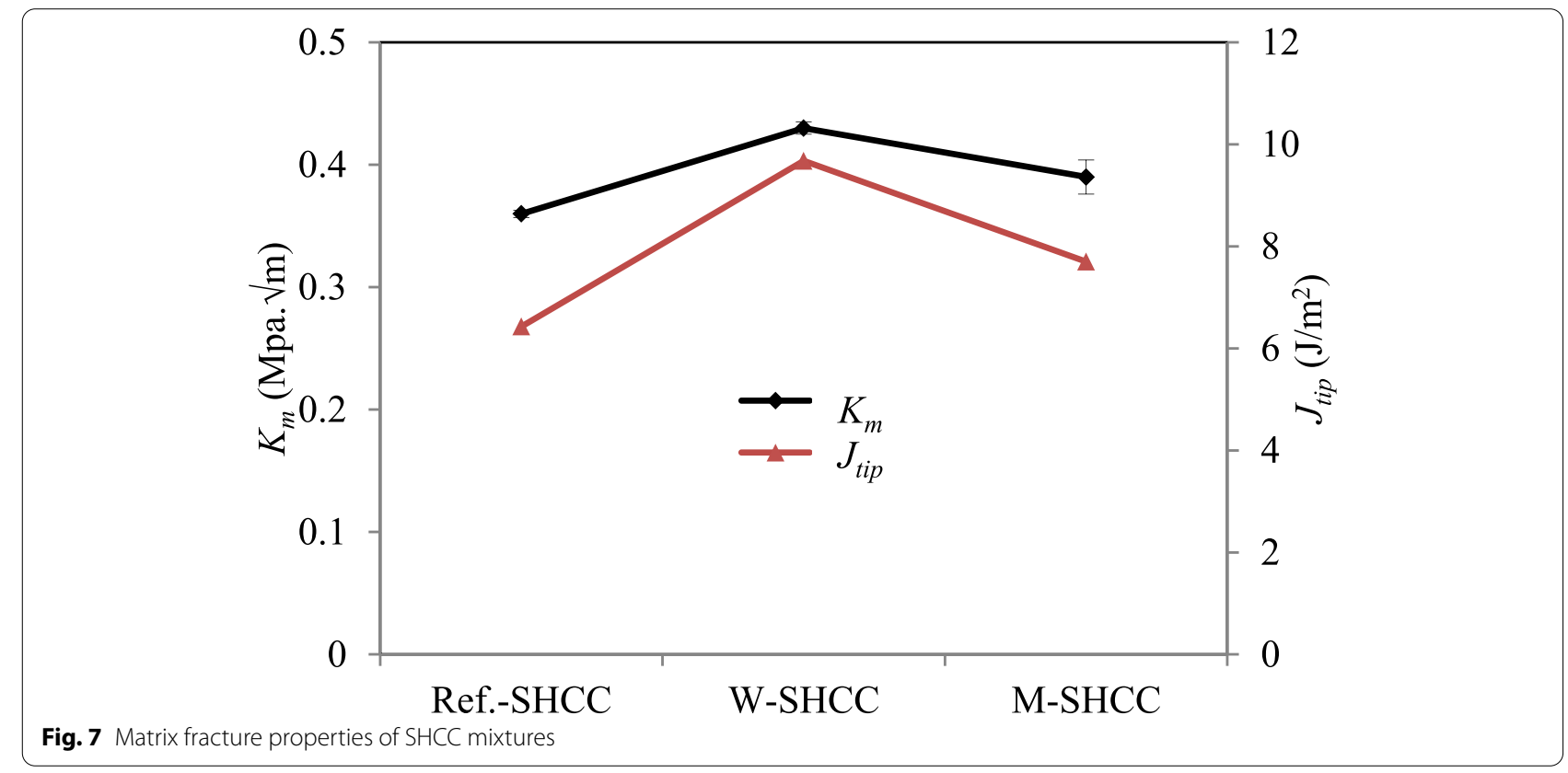


limiting matrix toughness $\left(U_{t i p}\right)$ or increasing the complimentary energy $\left(J_{b}{ }^{\prime}\right)$. The low $J_{\text {tip }}$ value requires relative less energy to trigger a crack on SHCC, subsequently is profitable for the development of multiple cracks. The high $J_{b}$ ' value means it can have sufficient residue energy left other than energy consumed by fiber-bridging effect to trigger another crack at a new site on SHCC. With the former, it is easy to reach, such as incorporating defects into SHCCs or diminish cement usage [26, 33], nevertheless, the latter is considerably difficult with a given specific fiber type and dosage. The $J_{b}$ 'value is closely relevant to fiber/matrix interfacial properties. In this section, how the bacterial addition does affect SHCC matrix toughness and interactions between PVA fiber and its surrounding hydrates will be discussed.

Figure 7 presents the fracture properties of SHCC matrix. As can be seen, the addition of bacterial culture increased matrix toughness $\left(K_{m}\right)$ especially for W-SHCC, which explains the change trend of first cracking strength in SHCCs under tension. The crack tip toughness $\left(J_{\text {tip }}=K_{m}{ }^{2} / E_{m}\right)$ also shows the same tendency. The stiffness $\left(E_{m}\right)$ is defined as the slope of initial linear stage in tensile stress-strain curves of SHCC. Compared with Ref.-SHCC, the $J_{t i p}$ of W-SHCC and M-SHCC was increased by $50 \%$ and $20 \%$, respectively. Such the growth of $J_{\text {tip }}$ value means it needs more energy to advance crack tip propagate, which is undesirable for reaching saturated multiple-cracking phenomenon, and thus high ductility of SHCC.

Generally, pseudo strain hardening $\left(P S H=J_{b}{ }^{\prime} / J_{t i p}\right)$ index is employed to quantitate the margin between $J_{b}$ 'and $J_{t i p}$, the higher $P S H$ value denotes a better chance to initiate more cracks on SHCC, subsequently higher tensile strain capacity. In addition to $J_{t i p}$, the $J_{b}$ ' that deduced from fiber/matrix interfacial parameters is the other decisive factor to $P S H$ value. Figure 8 (a) (c) display the fiber/matrix interfacial parameters of SHCC mixtures. It can be found from Fig. 8 (a) that the chemical bond $\left(G_{\mathrm{d}}\right)$ between PVA fiber and matrix dropped significantly upon bacterial addition. The mean $G_{d}$ value of Ref.SHCC, W-SHCC, and M-SHCC is $4.55 \mathrm{~J} / \mathrm{m}^{2}, 1.61 \mathrm{~J} / \mathrm{m}^{2}$, and $0.37 \mathrm{~J} / \mathrm{m}^{2}$, respectively. Compared with Ref.-SHCC, the $G_{\mathrm{d}}$ value of W-SHCC and M-SHCC was reduced by $65 \%$ and $92 \%$, respectively. Such low $G_{d}$ value is expected to avail the PVA fiber to debond from its surround blocks without rupture, thereby enhances the fiber-bridging effect, and furthermore conduce the buildup of $J_{b}$. The decrement of $G_{\mathrm{d}}$ value in SHCCs is probably due to the attached bacterial cells and their metabolic products on surface of PVA fiber that as shown in Fig. 9. Aside from the oil-coating on PVA fiber, the attached substances may alleviate the reaction between $\mathrm{Ca}^{2+}, \mathrm{Al}^{3+}$ in SHCC paste and hydroxyl in PVA bulk polymers, thus prevent

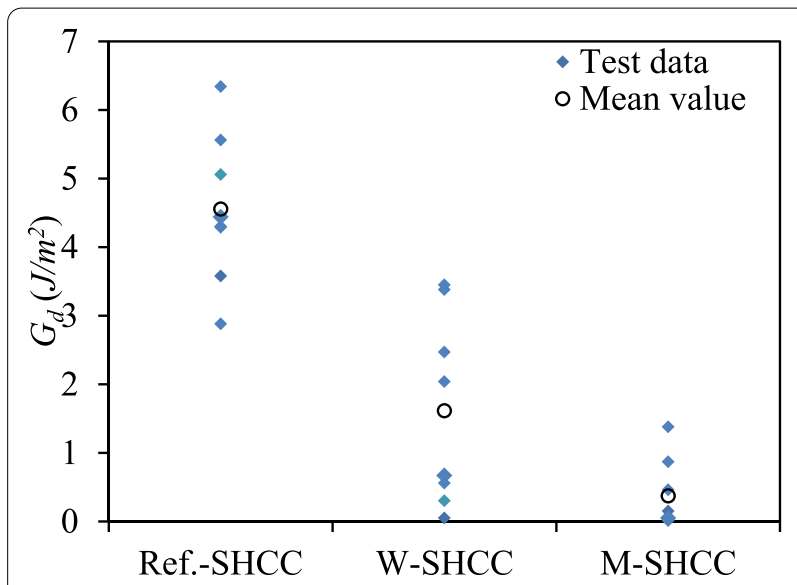

(a)

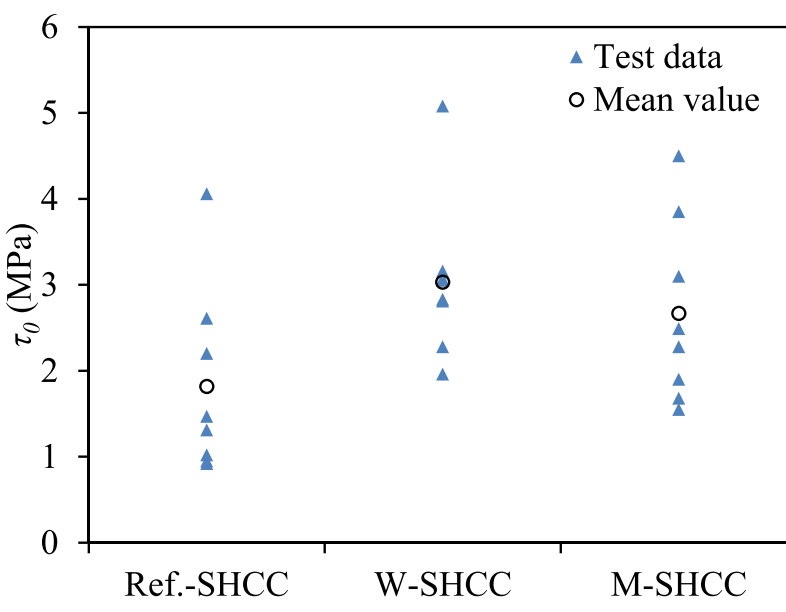

(b)

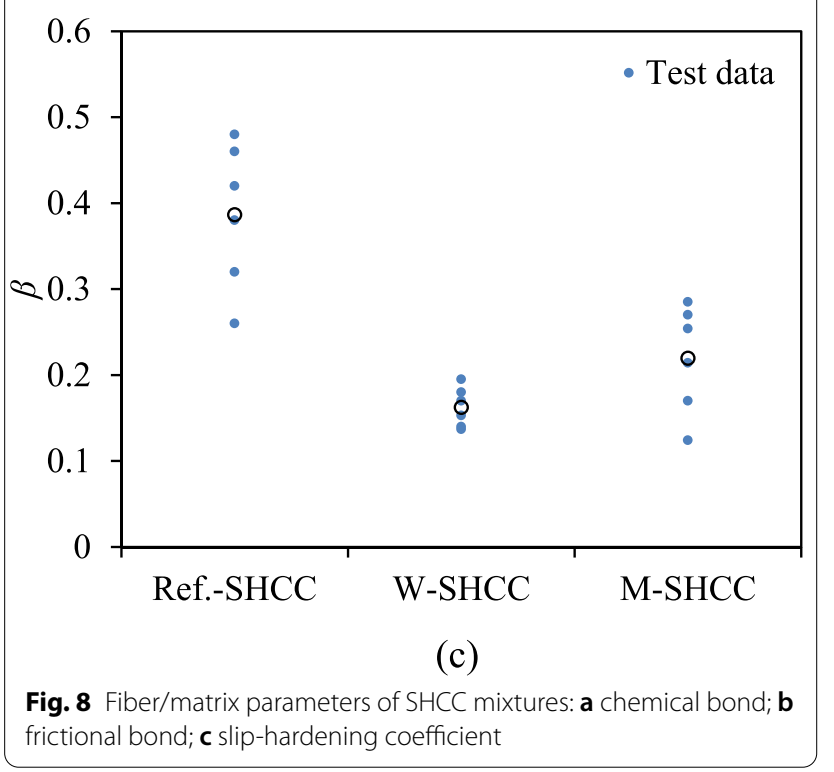




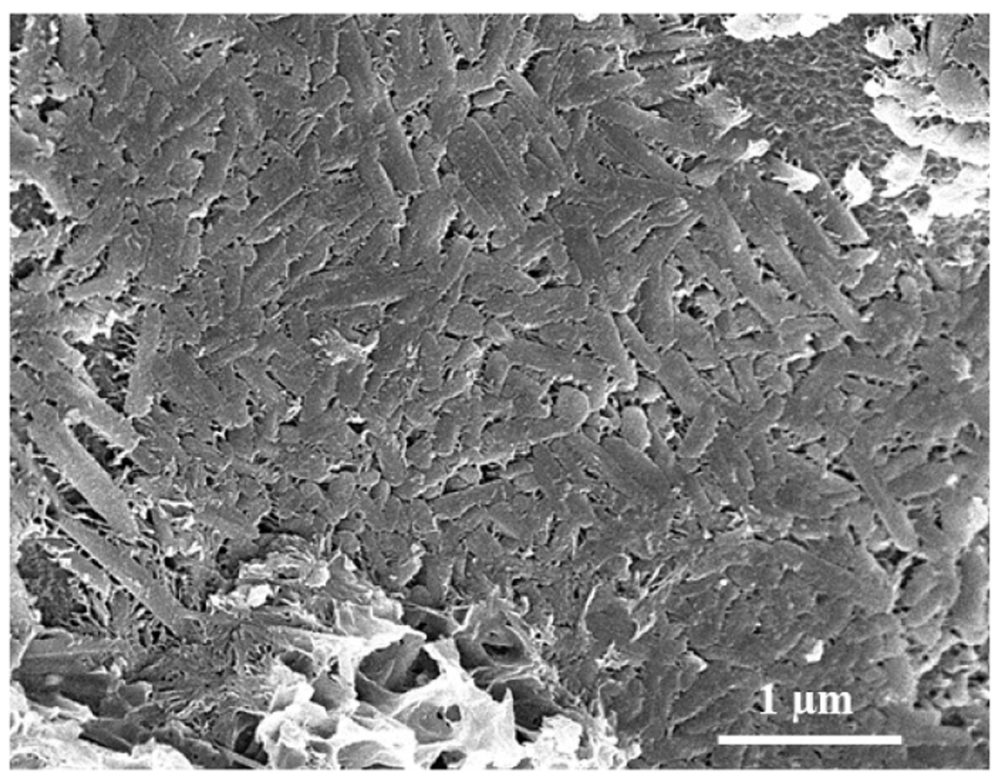

Fig. 9 Image of fiber surface for W-SHCC

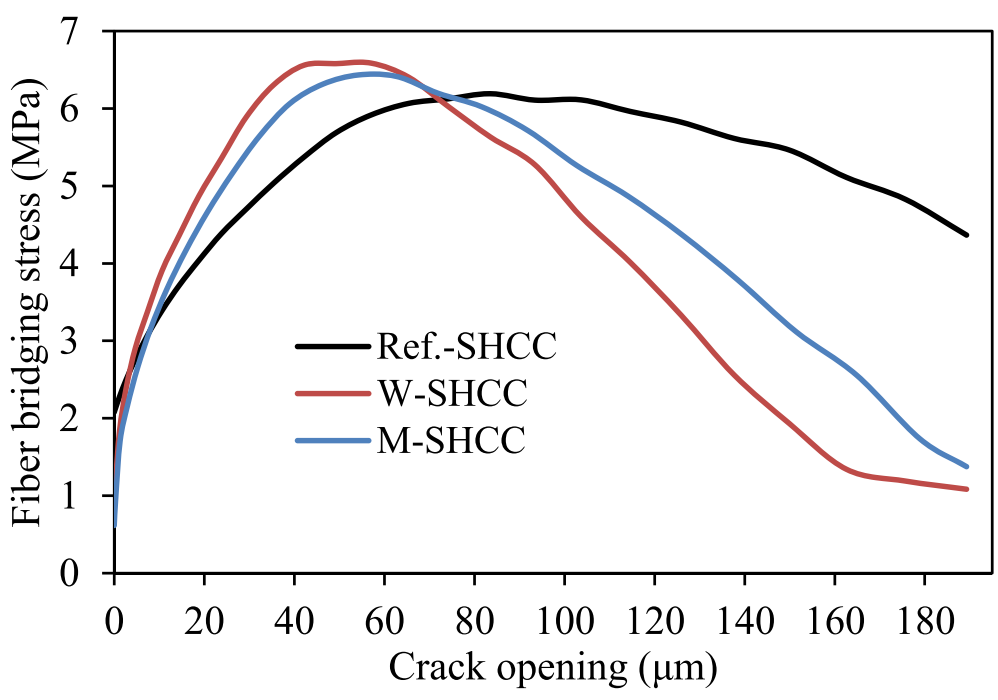

Fig. 10 Theoretical relationships between fiber bridging stress and crack opening

formation of strong chemical bond [34]. It's worthwhile to note that the substantial reduction of $G_{\mathrm{d}}$ upon simply adding bacteria is of great significance for the modification of PVA fiber surface, after all, researchers have paid tremendous efforts to reduce $G_{\mathrm{d}}$ during the historical SHCC development [35].

As shown in Fig. $8(\mathrm{~b})$, the frictional bond $\left(\tau_{0}\right)$ reveals the opposite tendency with $G_{d}$. Compared with that of $1.82 \mathrm{MPa}$ in Ref.-SHCC, the $\tau_{0}$ value increased to 3.03 $\mathrm{MPa}$ in W-SHCC and 2.67 MPa in M-SHCC, which increased by $66 \%$ and $47 \%$, respectively. The frictional bond $\left(\tau_{0}\right)$ between fiber and matrix is highly dominated by the denseness and hardness of interfacial transition zone (ITZ). In the preceded sections, it reported that the bacterial inclusion enhanced the fracture toughness and strength of matrix that implies a more compacted/tough matrix, of which the fiber is more difficult to slide against its surrounding matrix, and consequently resulted in a higher $\tau_{0}$. In another aspect, the slip-hardening coefficient $(\beta)$ was diminished due to the addition of bacteria, indicating that the fiber can slip-out with less damage or rupture, which is favorable to fiber-bridging properties. 
Table 3 The calculated $J_{b}{ }^{\prime}$ value and PSH index

\begin{tabular}{lccc}
\hline Mixtures & Ref.-SHCC & W-SHCC & M-SHCC \\
\hline$J_{b}{ }^{\prime}$ & 100.39 & 78.44 & 85.06 \\
$P S H\left(=J_{b}{ }^{\prime} / J_{t i p}\right)$ & 15.61 & 8.12 & 11.01 \\
\hline
\end{tabular}

Based on the above measured interfacial parameters, the theoretical development of fiber bridging stress versus cracking opening can be derived using micromechanics theory [36]. Figure 10 presents the theoretical fiber bridging stress-crack opening $(\sigma-\delta)$ curves of SHCC mixtures. From Fig. 10, it can be observed that the bacterial addition render the curves shift towards upper-left that caused the increase of maximal fiber bridging stress. This phenomenon well explains the enhancement of tensile strength of SHCCs.

From the $\sigma-\delta$ curves, the complementary energy $\left(J_{b}{ }^{\prime}\right)$ can be obtained. Table 3 lists the computed $J_{b}$ ' value and $P S H$ index of SHCC mixtures. It is found that the inclusion of bacterial culture lower $J_{b}$ ' value. The diminution of $G_{d}$ value is likely to decline the intersection value between $\sigma-\delta$ curves and Y-axle as displayed in Fig. 9, which assists the increment of $J_{b}$ ' value. On the contrary, the improved $\tau_{0}$ caused the $\sigma-\delta$ curves to move towards left in Fig. 10, which is detrimental to the gaining of $J_{b}$ ' value. Conclusively, combining the above two competitive efforts resulted in the decrement of $J_{b}$ ' value. More than that, as previously mentioned, the $J_{t i p}$ was boost due to the bacterial addition. Considering the tendency of $J_{b}$ ' and $J_{t i p}$ value, the $P S H$ index will assuredly decrease as a consequence of bacterial addition. Notwithstanding, as summarized in Table 3, the $J_{b}$ ' and PSH value in M-SHCC is comparatively higher to that of W-SHCC. The PSH index keeps the same change trend as that of strain capacity of SHCCs, which again demonstrated the proportional relation between them.

\section{Conclusions}

In this paper, the mechanical performance of SHCC with directly adding bacteria was investigated experimentally. The bacterial addition highly affected the mechanical performance of SHCCs. At composite level, the bacterial metabolism in SHCCs boosted the gaining of strength including compressive, first cracking, and tensile strength. On the contrary, the tensile strain capacity of SHCC containing bacterial cells exhibited lower value to that of reference SHCC mix. Between the Bacillus halodurans and its mutant strain, the SHCC with addition of mutant bacterial cells showed a relatively higher tensile strain capacity. At micro-scale level, on a par with the enhanced strength properties, the fracture toughness of matrix was also improved in bacteria-SHCCs. In term of fiber/matrix interfacial properties, it is noticeable that the bacterial addition effectively alleviated the formation of intense chemical bond between PVA fiber and its surrounding cementitious matrix as well as the slip-hardening coefficient, in another aspect, the interface frictional bond was increased which prevailed the positive effect from the decreased chemical bond, as a result, caused the decrease of complimentary energy $\left(J_{b}{ }^{\prime}\right)$ that is critical to ductility of SHCCs.

\section{Acknowledgements \\ Not applicable.}

\section{Authors' contributions}

Zhigang Zhang: Conceptualization, Methodology, Validation, Data curation, Writing - original draft. Dawei Liu: Data curation. Yuanzhao Ding: Validation, Data curation. Shuping Wang: Methodology, Validation, Writing - review \& editing. The author(s) read and approved the final manuscript.

\section{Funding}

Zhigang Zhang would like to thank the National Key R\&D Program of China (Grant No. 2021YFF0500804), the National Natural Science Foundation of China (Grant No. 52078083), and the Fundamental Research Funds for the Central Universities (Grant No. 2021CDJQY-008) for partial support of this work.

Availability of data and materials

All data have been presented in the Paper.

\section{Declarations}

Ethics approval and consent to participate Not applicable.

\section{Consent for publication}

Not applicable.

\section{Competing interests}

The authors declare no conflicts of interest.

\section{Author details}

${ }^{1}$ School of Civil Engineering, Chongqing University, Chongqing 400045, People's Republic of China. ${ }^{2}$ School of Civil and Environmental Engineering, Nanyang Technological University, Singapore, Singapore. ${ }^{3}$ College of Materials Science and Engineering, Chongqing University, Chongqing 400045, China.

Received: 3 January 2022 Accepted: 8 February 2022

Published online: 22 February 2022

\section{References}

1. Li VC, Wang S, Wu C (2001) Tensile Strain-hardening Behavior of PVA-ECC. ACl Mater J 98(6):483-492

2. Zhang Z, Yang F, Liu J, Wang SP (2020) Eco-friendly high strength, high ductility engineered cementitious composites (ECC) with substitution of fly ash by rice husk ash. Cement \& Concrete Research. 137:106200

3. Zhang Z, Liu S, Yang F, Weng Y, Qian S (2021) Sustainable high strength, high ductility engineered cementitious composites (ECC) with substitution of cement by rice husk ash. Journal of Cleaner Production. 317:128379

4. Ding Y, Yu K, Li M (2022) A review on high-strength engineered cementitious composites (HS-ECC): Design, mechanical property and structural application. Structures 35:903-921

5. Cai Z, Liu F, Yu J, Yu K, Tian L (2021) Development of ultra-high ductility engineered cementitious composites as a novel and resilient fireproof coating. Construction and Building Materials. 288:123090 
6. Qin F, Zhang Z, Yin Z, Di J et al (2020) Use of high strength, high ductility engineered cementitious composites (ECC) to enhance the flexural performance of reinforced concrete beam. Journal of Building Engineering. 32:101746

7. Zhang Z, Zhang Q, Li VC (2019) Multiple-scale investigations on selfhealing induced mechanical property recovery of ECC. Cement Concr Compos 103:293-302

8. Zhang Z, Qian S, Liu H, Li VC (2017) Ductile concrete material with selfhealing capacity for jointless concrete pavement use. Transp Res Rec 2640(1):78-83

9. Kan L, Shi H, Sakulich A, Li VC (2010) Self-Healing Characterization of Engineered Cementitious Composite Materials. ACI Mater J 107(6):617-624

10. Khaliq W, Ehsan MB (2016) Crack healing in concrete using various bio influenced self-healing techniques. Construction and building materials 102(1):349-357

11. Wang J, De Belie N, Verstraete W (2012) Diatomaceous earth as a protective vehicle for bacteria applied for self-healing concrete. J Ind Microbiol Biotechnol 39(4):567-577

12. Bhaskar S, Hossain KMA, Lachemi M et al (2017) Effect of self-healing on strength and durability of zeolite-immobilized bacterial cementitious mortar composites. Cement Concr Compos 82:23-33

13. Alazhari M, Sharma T, Heath A, Cooper R, Paine K (2018) Application of expanded perlite encapsulated bacteria and growth media for selfhealing concrete. Constr Build Mater 160:610-619

14. Wang J, Van Tittelboom K, De Belie N, Verstraete W (2012) Use of silica gel or polyurethane immobilized bacteria for self-healing concrete. Constr Build Mater 26(1):532-540

15. Krishnapriy S, Babu D, Arulraj P (2015) Isolation and identification of bacteria to improve the strength of concrete. Microbiol Res 174:48-55

16. Pei R, Liu J, Wang S, Yang M (2013) Use of bacterial cell walls to improve the mechanical performance of concrete. Cement Concr Compos 39:122-130

17. Ghosh S, Biswas M, Chattopadhyay BD, Mandal S (2009) Microbial activity on the microstructure of bacteria modified mortar. Cement Concr Compos 31(2):93-98

18. Ghoneim A, Hassan H, Aboul-Nour L (2020) Self-repairing polyethylene fiber-reinforced-concrete with bacillus subtilis bacteria a review. International Journal of Engineering \& Technology 9(2):437-447

19. Ganesh A, Muthukannan M, Malathy R, Babu C (2019) An experimental study on effects of bacterial strain combination in fibre concrete and selfhealing efficiency. KSCE J Civ Eng 23(10):4368-4377

20. Karimi N, Mostofinejad D (2020) Bacillus subtilis bacteria used in fiber reinforced concrete and their effects on concrete penetrability. Construction and Building Materials. 230:117051

21. Zhang D, Shahin M, Yang Y, Liu H, Cheng L (2022) Effect of microbially induced calcite precipitation treatment on the bonding properties of steel fiber in ultra-high performance concrete. Journal of Building Engineering. https://doi.org/10.1016/j.jobe.2022.104132

22. Ghoniem A, Hassan H, Aboul-Nour L (2021) Behavior of Macro-Synthetic Fiber-Reinforced High-Strength Concrete Beams Incorporating Bacillus subtilis Bacteria. Latin American Journal of Solids and Structures. 18(3):e359

23. Zhang Z, Ding Y, Qian S (2019) Influence of bacterial incorporation on mechanical properties of engineered cementitious composites (ECC). Constr Build Mater 196:195-203

24. Zhang Z, Liu J, Xu X, Yuan L (2020) Effect of sub-elevated temperature on mechanical properties of ECC with different fly ash contents. Construction and Building Materials. 262:120096

25. Zhang Z, Qian S, Ma H (2014) Investigating mechanical properties and self-healing behavior of micro-cracked ECC with different volume of fly ash. Constr Build Mater 52:17-23

26. Zhang Z, Yuvaraj A, Di J, Qian S (2019) Matrix design of light weight, high strength, high ductility ECC. Constr Build Mater 210:188-197

27. Ding Y, Peng N, Du Y, Ji L, Cao B (2014) Disruption of Putrescine Biosynthesis in Shewanella oneidensis Enhances Biofilm Cohesiveness and Performance in $\mathrm{Cr}(\mathrm{VI})$ Immobilization. Appiled and Environmental Microbiology 80(4):1498-1506

28. Zhang Z, Weng Y, Ding Y, Qian S (2019) Use of genetically modified bacteria to repair cracks in concrete. Materials 12(23):3912

29. ASTM (ASTM International) C109 / C109M-2 (2014) Standard Test Method for Compressive Strength of Hydraulic Cement Mortars, West Conshohocken.
30. ASTM (ASTM International) E399 - 12 (2014) Standard test method for linear-elastic plane-strain fracture toughness $\mathrm{K}_{\mathrm{lc}}$ of metallic materials, West Conshohocken.

31. Zhang Z, Zhang Q (2018) Matrix tailoring of Engineered Cementitious Composites (ECC) with non-oil-coated, low tensile strength PVA fiber. Constr Build Mater 161:420-431

32. Sato T, Diallo F (2010) Seeding Effect of Nano-CaCO3 on the Hydration of Tricalcium Silicate. Transp Res Rec 2141:61-67

33. Zhang Z, Qin F, Ma H, Xu L (2020) Tailoring an impact resistant engineered cementitious composite (ECC) by incorporation of crumb rubber. Construction and Building materials. 262:120116

34. Gulgun MA, Kriven WM, Tan LS, McHugh AJ (1995) Evolution of mechano-chemistry and microstructure of a calcium aluminate-polymer composite: part I. Mixing time effects. Journal of Material Research. 10(7):1746-1755

35. Li VC, Wu C, Wang S, Ogawa A, Saito T (2002) Interface tailoring forstrainhardening polyvinyl alcohol-engineered cementitious composite (PVAECC). ACl Mater J 99(5):463-472

36. Yang EH, Wang S, Yang Y, Li VC (2008) Fiber-bridging Constitutive Law of Engineered Cementitious Composites. J Adv Concr Technol 6(1):181-193

\section{Publisher's Note}

Springer Nature remains neutral with regard to jurisdictional claims in published maps and institutional affiliations.

\section{Submit your manuscript to a SpringerOpen ${ }^{\circ}$ journal and benefit from:}

- Convenient online submission

- Rigorous peer review

- Open access: articles freely available online

- High visibility within the field

Retaining the copyright to your article

Submit your next manuscript at springeropen.com 